\title{
Describing Intravenous Extravasation in Children (DIVE Study)
}

\author{
Vanessa Paquette, Rumi McGloin, Tracie Northway, Pia DeZorzi, Avash Singh, and Roxane Carr
}

\begin{abstract}
Background: Extravasation, the inadvertent leakage of intravenous (IV) medication from the vein into the surrounding tissue, is a iatrogenic cause of patient injury. Extravasation has been reported to occur in $0.1 \%$ to $6.5 \%$ of hospital inpatients. The incidence may be higher among children because they have multiple risk factors, including small and fragile veins, decreased peripheral circulation, capillary leakage, and flexible subcutaneous tissue.
\end{abstract}

Objectives: To describe the incidence of extravasation at a pediatric tertiary care hospital, to identify the agents causing extravasation, and to describe the use of antidotes to manage identified cases. A secondary objective was to describe adverse drug effects associated with the antidotes administered.

Methods: The medical records of pediatric patients with documented extravasation of an IV medication between January 1, 2006, and August 31, 2008, were analyzed retrospectively. The appropriateness of antidote use was determined in terms of adherence to the institution's protocol for treatment of extravasation.

Results: A total of 42 patients had documented extravasation, for an overall incidence of $0.04 \%$ per patient-day. Of the 40 cases in which location was documented, $12(30 \%)$ occurred on the general pediatric wards, $10(25 \%)$ on the surgical ward, $9(22 \%)$ in the neonatal intensive care unit, $5(12 \%)$ in the pediatric intensive care unit, $3(8 \%)$ in day care, and $1(2 \%)$ in the emergency department. The most common medications involved were fluids for IV administration (18 [43\%]), potassium chloride $(11[26 \%])$, antibiotics $(8[19 \%])$, total parenteral nutrition (8 [19\%]), calcium chloride (2 [5\%]), and epinephrine (2 [5\%]). Multiple drugs were involved in some cases of extravasation. The decision to administer an antidote and the choice of antidote (if required) were appropriate in $50 \%$ of the cases. No adverse drug effects were reported with use of antidotes.

Conclusions: The incidence of extravasation was low. The medications most commonly involved were similar to those reported in the literature. Antidotes were well tolerated but were appropriately used in only half of the events. Prospective trials are needed to determine the clinical severity of injury and to assess the effectiveness and safety of antidotes.

Key words: extravasation, IV medications, pediatrics, hyaluronidase

Can J Hosp Pharm 2011;64(5):340-345

\section{RÉSUMÉ}

Contexte : L'extravasation, la fuite accidentelle d'un liquide administré par voie intraveineuse dans le tissu environnant, est une cause iatrogène de lésions causées aux patients. On a signalé des cas d'extravasation chez 0,1 à $6,5 \%$ des patients hospitalisés, et ce pourcentage pourrait être plus élevé chez les enfants, à cause des multiples facteurs de risque dans cette population, dont des petits vaisseaux fragiles, une circulation périphérique réduite, une hyperperméabilité capillaire et la flexibilité du tissu sous-cutané.

Objectifs : Décrire l'incidence d'extravasation dans un hôpital de soins tertiaires pour enfants, déterminer les agents qui en sont responsables et décrire l'emploi des antidotes pour prendre en charge ces cas. Un objectif secondaire était de décrire les effets indésirables associés aux antidotes administrés.

Méthodes : Une analyse rétrospective des dossiers médicaux faisant état d'extravasation d'un médicament administré par voie intraveineuse chez des enfants hospitalisés à l'établissement des auteurs entre le $1^{\text {er }}$ janvier 2006 et le 31 août 2008 a été effectuée. La pertinence de l'emploi des antidotes a été déterminée en termes de conformité au protocole de l'établissement pour la prise en charge spécifique des cas d'extravasation.

Résultats : Des cas d'extravasation étaient consignés chez un total de 42 patients, pour un taux d'incidence global de 0,04\% par journée-patient. Des 40 cas pour lesquels le lieu où s'est produit l'incident a été noté, 12 (30\%) sont survenus dans le service de pédiatrie générale, 10 (25\%) dans le service chirurgical, 9 (22\%) dans l'unité de soins intensifs néonatals, 5 (12\%) dans l'unité de soins intensifs pédiatriques, 3 (8\%) dans le centre de jour et $1(2 \%)$ dans le service des urgences. Les produits les plus souvent associés aux cas d'extravasation étaient les liquides pour perfusion intraveineuse (18 [43\%]), le chlorure de potassium (11 [26\%]), les antibiotiques (8 [19\%]), l'alimentation parentérale totale (8 [19\%]), le chlorure de calcium $(2[5 \%])$ et l'épinéphrine (2 [5\%]). Plus d'un médicament était en cause dans certains cas d'extravasation. La décision d'administrer un antidote et, le cas échéant, le choix de l'antidote étaient appropriés dans $50 \%$ des cas. Aucun effet indésirable associé à l'emploi des antidotes n'a été observé.

Conclusions : Les cas d'extravasation étaient rares. Les produits les plus souvent mis en cause étaient similaires à ceux décrits dans la littérature. Les antidotes étaient bien tolérés, mais n'étaient appropriés que dans la moitié des cas. Des études prospectives sont nécessaires afin de déterminer la gravité des préjudices sur le plan clinique et d'évaluer l'efficacité et l'innocuité des antidotes.

Mots clés : extravasation, médicaments intraveineux, pédiatrie, hyaluronidase

[Traduction par l'éditeur] 


\section{INTRODUCTION}

$\mathrm{E}$ xtravasation is the inadvertent administration of intravenous (IV) medication from the vein into surrounding tissue either by leakage or direct exposure caused by poor cannula placement and venipuncture techniques. ${ }^{1}$ The reported incidence of extravasation among hospital inpatients is $0.1 \%$ to $6.5 \%$, and the true incidence is likely higher because of inconsistent documentation and reporting. ${ }^{2-4}$ Extravasation injuries initially present as local swelling, erythema, blistering, and pain. These injuries can lead to severe and progressive destruction of the tissue, including tissue necrosis, and can ultimately interfere with the function of the affected extremity or result in amputation. ${ }^{1,2}$ Therefore, injuries resulting from extravasation are considered to constitute a medical emergency and necessitate immediate treatment. ${ }^{1-5}$

Identified risk factors in patients of all ages include insertion of the cannula and administration of the medication by inexperienced staff; venipuncture and cannula placement in small, fragile veins in the vicinity of joints (particularly in elderly patients and children); multiple venipuncture attempts at a given site because the number of easily visualized peripheral veins is limited; and presence of decreased perfusion. ${ }^{2}$ Children commonly have multiple risk factors, which increases the likelihood of IV extravasation injuries. Although children of all ages receiving IV therapy are at greater risk of extravasation injury than adults, neonates have additional factors that may increase the severity of injury, such as poor venous integrity, capillary leakage, decreased peripheral circulation, and more flexible subcutaneous tissue, which can expand quickly with infiltration of fluid. An additional risk for children is that a small volume of extravasated IV fluid has the potential to cause substantial tissue damage secondary to local pressure effects and compartment syndromes. ${ }^{6}$

Common sites of extravasation injuries in neonatal and pediatric patients include the dorsum of the hand, the forearm, the cubital fossa, and the dorsum of the foot. These are the areas of the body where the skin and subcutaneous tissue are thinnest, which makes them the most suitable sites for IV access but also the most susceptible to injury. ${ }^{6}$ However, no site is immune from the possibility of an extravasation injury.

IV fluids and medications commonly implicated in extravasation injuries include parenteral nutrition fluids, cytotoxic drugs, vasopressors, inotropes, electrolytes (e.g., calcium chloride), and hyperosmolar medications (e.g., mannitol). ${ }^{5}$ The severity of extravasation injury is often proportional to the amount of drug extravasated, but properties of the medication, such as $\mathrm{pH}$, osmolarity, and molecular weight, will also affect the degree of tissue damage. ${ }^{2}$

Strategies to prevent extravasation include following strict nursing protocols for IV administration, ensuring secure cannula placement, checking frequently (hourly) for early signs of infiltration, monitoring infusion volumes and infusion pump pressures, and educating nursing staff appropriately about the signs and symptoms of extravasation. ${ }^{6}$ Despite policies and procedures to minimize extravasation and published guidelines on prevention, ${ }^{6}$ extravasation of medications continues to occur. Unfortunately, there are few studies and guidelines to assist and guide health care professionals once an extravasation injury has occurred. Most authors have suggested local comfort measures, local antidotes and debridement, or other surgical interventions. . $^{1,6}$,

The authors' institution, a tertiary care pediatric hospital, has developed a protocol for treating extravasation injuries by means of two specific antidotes according to the medication involved (see Appendix 1, available at www.cjhp-online.ca/ index.php/cjhp/issue/view/83/showToc). Hyaluronidase, which is available in Canada through the Special Access Programme of Health Canada, is an enzyme that increases the permeability of tissues through hydrolysis of hyaluronic acid and thus facilitates the systemic absorption of infiltrated agents. Phentolamine, a nonspecific $\alpha$-adrenergic blocker, antagonizes the actions of $\alpha$-adrenergic drugs by reversing vasoconstriction, allowing the drugs to be absorbed.

For extravasation of chemotherapy medications, antidotes are based on the treatment protocol of the BC Cancer Agency ${ }^{7}$ and the extravasation guidelines of the Children's Oncology Group. Sodium thiosulphate is thought to neutralize the alkylating agent mechlorethamine, and it chemically inactivates cisplatin. ${ }^{8}$ Topical dimethyl sulphoxide has antioxidant and anti-inflammatory properties that are thought to limit the extent of local tissue damage. ${ }^{8}$ Dexrazoxane inactivates anthracyclines by inhibiting topoisomerase II. ${ }^{8}$

Data supporting the use of specific antidotes has come primarily from animal studies and case reports in humans. ${ }^{2}$ However, case reports of extravasation treatment in the pediatric population have focused on cleansing, debridement, and surgical interventions. ${ }^{1,9}$ Details are lacking about interventions involving medication, and only minimal information on dose, frequency, duration, and administration procedure is available. Furthermore, only vague descriptions have been provided of the resulting tissue damage after the interventions have been applied. Thus, the true effectiveness of treatment modalities remains unknown. Prospective human clinical trials have been conducted for antidotes to address extravasation due to chemotherapy medications, but these clinical trials have been limited to adults, and evidence is lacking for use of these antidotes in the pediatric population..$^{10,11}$

The objectives of this study were to describe the incidence of extravasations (as the rate per patient-days) at the authors' institution, to identify the agents causing extravasation injuries, to describe the use of antidotes to manage the identified 
extravasations, and to assess the appropriateness of antidote use. The secondary objective was to describe adverse reactions to the antidotes administered.

\section{METHODS}

This study was undertaken at the Children's and Women's Health Centre of British Columbia, a 240-bed tertiary care institution in Vancouver, British Columbia. Following receipt of approval from the University of British Columbia / Children's and Women's Health Centre of British Columbia Research Ethics Board, a retrospective analysis was undertaken of the medical records of patients with a documented extravasation event involving an IV medication or fluid. Patients were identified through the Patient Safety Learning System (a computerized reporting system used by health care providers in British Columbia to report adverse events), the pharmacy's dispensing records for medication therapies to treat extravasation, and databases maintained by individual medical programs within the institution.

The study included patients 18 years of age or younger with a documented extravasation event (as defined in Appendix 1) between January 1, 2006, and August 31, 2008. This start date was chosen because a computerized system for documenting adverse events was introduced at the hospital at the beginning of 2006. At that time, hospital staff were made aware of and were educated about the importance of reporting adverse events, including extravasation injuries, and the administration's expectation that they would do so.

One investigator (V.P.), using a standardized data collection form, obtained the following information from patients' medical records and standardized extravasation injury reports: demographic characteristics, medical problems and diagnoses, medication(s) extravasated, personnel who administered the medication(s), IV site, location of injury, time from identification of extravasation to initiation of treatment, antidote given, other interventions specific to the extravasation injury, and any adverse effects related to the antidote treatment. The adverse effects of hyaluronidase include tachycardia, hypotension, dizziness, chills, nausea, vomiting, urticaria, angioedema, and anaphylactic reactions. The adverse effects of locally administered phentolamine include tachycardia and hypotension. Both tachycardia and hypotension are frequently monitored and documented as part of routine assessment of patients' vital signs, but dizziness, chills, and nausea are difficult to assess in pediatric patients. Vomiting is routinely monitored and documented. Urticaria, angioedema, and anaphylactic reactions are severe adverse effects and would be documented in the medical record. The appropriateness of management following an extravasation event was determined by the same investigator using the criteria described in the institution's extravasation treatment protocol (see Appendix 1).
Descriptive statistics are used to report patients' demographic information, to characterize the types of medications involved in extravasation injuries (causative agents and antidotes), and to report the adverse effects of the antidotes administered. The incidence of extravasation was calculated per number of inpatient days for all patients admitted to the hospital during the study period. Subgroup analyses were based on patient age categories (premature neonate, $<40$ weeks gestational age; neonate, 40-44 weeks gestational age; infant, 1-12 months; child, 1-12 years; adolescent, $12-18$ years) and the medical program caring for the patient at the time of the extravasation injury (neonatal intensive care unit, pediatric intensive care unit, oncology, and general pediatrics).

\section{RESULTS}

Forty-two patients were identified as having experienced an extravasation injury during the study period (Table 1). The overall incidence of extravasation was $0.04 \%$ per patient-day.

According to the a priori subgroup analyses describing the frequency of extravasation by age group and medical ward, extravasation incidents were reported most frequently among infants 1-12 months of age and children 1-12 years of age (about $40 \%$ in each group) and on the general pediatric wards (30\%) (Table 1).

The majority of extravasations involved peripheral IV catheters $(41[98 \%])$. Among these cases, the most common site for extravasation was the right hand (12 cases [29\%]) (Table 1). Extravasation from central IV catheters was infrequent ( 1 case $[2 \%])$.

The most common medications involved were IV fluids (18 [43\%]), potassium chloride (11 [26\%]), antibiotics (8 [19\%]), total parenteral nutrition (8 [19\%]), calcium chloride (2 [5\%]), and epinephrine (2 [5\%]) (Table 2). All total parenteral nutrition solutions were without lipids (2-in-1 formulation: dextrose and amino acids with electrolytes). The concentration of calcium chloride was $0.136 \mathrm{mmol} / \mathrm{mL}$, and the maximum concentration of potassium chloride administered through a peripheral line was $0.1 \mathrm{mmol} / \mathrm{mL}$. The medications causing extravasation were not always documented in the chart or incident report; in that situation, data were obtained from the medication administration record. Medications and fluids were documented separately in the medication administration record; however, some medications and fluids were being co-infused through the same line when the extravasation injury occurred, which made it difficult to determine the offending agent.

For $21(50 \%)$ of the 42 patients, management of the extravasation of IV medication was appropriate (i.e., followed the institutional protocol). According to the protocol, 34 patients $(81 \%)$ should have received an antidote; however, only 14 patients (33\%) received an antidote. Of these 14 patients, all were deemed to have required an antidote, but only 13 of 
Table 1. Demographic Characteristics of 42 Pediatric Patients Who Experienced an Extravasation Event

\begin{tabular}{|c|c|}
\hline Characteristic & $\begin{array}{l}\text { No. (\%) of Patients } \\
\text { or Median (Range) }\end{array}$ \\
\hline $\begin{array}{r}10 \\
(0.07-216\end{array}$ & $\begin{array}{r}10 \text { months } \\
\text { (0.07-216 months) }\end{array}$ \\
\hline \multicolumn{2}{|l|}{ Age group } \\
\hline Premature neonate (< 40 weeks GA) & $4(10)$ \\
\hline Neonate (40-44 weeks GA) & $2(5)$ \\
\hline Infant (1-12 months) & $16(38)$ \\
\hline Child (1-12 years) & $17(40)$ \\
\hline Adolescent (12-18 years) & $3(7)$ \\
\hline Weight $(\mathrm{kg})$ & $7.7 \quad(1-65)$ \\
\hline Length of stay (days) & $7.5(1-140)$ \\
\hline Sex, male & $21(50)$ \\
\hline \multicolumn{2}{|l|}{ Admission diagnosis $(n=41)$} \\
\hline Gastrointestinal & $12(29)$ \\
\hline Prematurity & $7(17)$ \\
\hline Pneumonia & $5(12)$ \\
\hline Postoperative & $4(10)$ \\
\hline Septic shock or sepsis & $4(10)$ \\
\hline Post-cardiac surgery & 2 (5) \\
\hline Other & $7(17)$ \\
\hline \multicolumn{2}{|c|}{ Ward where extravasation occurred $(n=40)$} \\
\hline General pediatric & $12(30)$ \\
\hline Surgical & $10(25)$ \\
\hline Neonatal ICU & $9(22)$ \\
\hline Pediatric ICU & $5(12)$ \\
\hline Day care unit & $3(8)$ \\
\hline Emergency department & $1(2)$ \\
\hline \multicolumn{2}{|l|}{ Location of peripheral IV line* $(n=41)$} \\
\hline Right hand & $12(29)$ \\
\hline Left hand & $8(20)$ \\
\hline Right foot & $8(20)$ \\
\hline Left foot & $5(12)$ \\
\hline Right arm & $3(7)$ \\
\hline Left arm & 1 (2) \\
\hline Right leg & $1 \quad(2)$ \\
\hline Left leg & $2(5)$ \\
\hline Scalp & $1 \quad(2)$ \\
\hline
\end{tabular}

$\mathrm{GA}=$ gestational age, ICU = intensive care unit.

${ }^{*}$ Cases involving peripheral catheters.

them received the correct antidote (hyaluronidase). The other patient also received hyaluronidase, but in that case the antidote was incorrect; the extravasated medication was epinephrine, so the antidote should have been phentolamine. Of the 28 patients (67\%) who did not receive an antidote, $20(71 \%)$ should have received an antidote, according to the protocol, whereas no antidote was required for 8 patients (29\%). In terms of the secondary outcome, no adverse effects were reported with use of hyaluronidase.

Data about the personnel who administered the medication that caused extravasation and the time from discovery of extravasation to treatment were not recorded in the medical records and therefore cannot be reported here.

\section{DISCUSSION}

Extravasation of IV medications is considered a medical emergency that can lead to serious outcomes if not treated

Table 2. Medications Involved in Extravasation Events in 42 Pediatric Patients

Medication

$5 \%$ dextrose in water

Potassium chloride

Total parenteral nutrition

$10 \%$ dextrose in water

Cephalosporin

Epinephrine

Calcium chloride

Sodium bicarbonate

Albumin

Phenytoin

Vancomycin

Cloxacillin

Ampicillin

Morphine

Lorazepam

IV immunoglobulin

Furosemide

*Percentages do not sum to 100 because in some cases, more than 1 medication was being infused via the same line when the extravasation occurred.

appropriately. Despite these implications, there is a lack of literature about extravasation injuries in the pediatric population. It has been documented that this population is at the highest risk for extravasation and subsequent injury. ${ }^{6}$ To the authors' knowledge, this study is one of the largest reviews of pediatric extravasation injuries to date.

The incidence of extravasation at this institution $(0.04 \%$ per patient-day) was lower than reported elsewhere in the literature. ${ }^{2-4}$ This difference could be a result of underreporting and/or differences in methods of calculating incidence. Unfortunately, many published studies about extravasation do not describe how incidence was calculated.

Several of the medical programs at the study institution use a reporting form for extravasation incidents, but this form is not implemented or enforced hospital-wide. Similarly, although reporting of adverse events in the hospital-wide computerized adverse event reporting system is strongly encouraged and is expected of staff when adverse events occur, reporting remains voluntary. The literature suggests that neonates have a greater risk of extravasation than older children and adults, ${ }^{6}$ but the largest group of extravasations in this study occurred in children 1-12 years of age. This could be a result of underreporting or because the "child" age group encompasses the greatest range of ages. More than half of the extravasations occurred on the surgical and general pediatrics wards, although it might be expected that this problem would be more frequent in critical care areas and oncology. This unexpected result may also be due to underreporting, or it might be relate to the fact that in these areas, medications are administered primarily via 
central venous lines, rather than peripheral venous lines, which would decrease the chances of extravasation. It has been reported that medications with high osmolarity, low $\mathrm{pH}$, and high molecular weight are more likely to cause injuries if there is interstitial infiltration. ${ }^{2}$ The medications most commonly causing extravasation in the current study were consistent with the literature and included fluids, electrolytes, total parenteral nutrition solutions, and vasopressors. Surprisingly, no chemotherapy agents were documented to cause extravasation injuries, despite the fact that most chemotherapy agents have the properties listed above.

The right hand was the most common site of documented extravasation, perhaps because the hand is a common location for placement of IV lines or because the upper extremities are involved in many movements, which would increase the risk of the line moving, leading to extravasation. Regardless, this finding could be useful to nursing staff in terms of prevention.

This study provides useful data for preventive strategies. However, the relationship between extravasation of particular medications and the clinical severity of the resulting injury cannot be determined from the results reported here.

As described above, the study institution has developed a treatment protocol for extravasation. The 2 available antidotes, hyaluronidase and phentolamine, are administered locally to the affected area, depending on the extravasated medication. The protocol has been implemented hospital-wide, but in this study, 20 (48\%) of the 42 patients did not receive an antidote, even though, according to the institutional protocol, they should have. This discrepancy between protocol and practice may be due to a lack of education and awareness of the treatment protocol for extravasation among staff and physicians. The need for education about use of the appropriate agent, depending on the medication that has been extravasated, is illustrated by the case in which hyaluronidase was administered for extravasation of epinephrine, whereas phentolamine should have been given.

Potential solutions to the lack of adherence to the extravasation treatment protocol at this institution include formal, hospital-wide implementation of a unified protocol; presentation of educational sessions to nurses, physicians, and pharmacists; and mandating that each time hyaluronidase or phentolamine is ordered, a pharmacist must call the ward to determine which medication caused the extravasation injury and to assess the appropriateness of the antidote. Reporting could be improved by using the institution's online medication incident reporting system to report cases of extravasation, and this could be specified as a step in the treatment protocol.

No adverse effects were reported with the use of hyaluronidase, but this may be a result of underreporting. The incident report form was filed in the patient's medical record for only 2 of the 42 cases, and there is no area on the form to report antidote-related adverse effects.
This study had some limitations. Given the study's retrospective nature, underreporting and inconsistent reporting of extravasation events may have biased the results. The data were based on a review of medical records, which might not have fully captured the decisions for using or not using an antidote in relation to the treatment protocol. Also, information about the severity and outcomes of the extravasation incidents could not be collected.

\section{CONCLUSIONS}

At a pediatric tertiary care institution, the incidence of extravasations was low. The medications most commonly involved were similar to those previously reported in the literature. Antidotes were well tolerated but were used appropriately in only $50 \%$ of the cases. The lack of adherence to the institution's extravasation treatment protocol raises concerns about lack of education and awareness about extravasation and its proper management. Before prospective trials are undertaken to determine clinical severity of injury and to assess the effectiveness and safety of antidotes, steps should be taken to increase education about extravasation and to enforce proper reporting and documentation of such events.

\section{References}

1. Kumar RJ, Pegg SP, Kimble RM. Management of extravasation injuries. ANZ J Surg 2001;71(5):285-289.

2. Camp-Sorrell D. Developing extravasation protocols and monitoring outcomes. J Intraven Nurs 1998;21(4):232-239.

3. Cartlidge PHT, Fox PE, Rutter N. The scars of newborn intensive care. Early Hum Dev 1990;21(1):1-10.

4. Wilkins CE, Emmerson AJB. Extravasation injuries on regional neonatal units. Arch Dis Child Fetal Neonatal Ed 2004;89(3):F274-F275.

5. Treatment of medication extravasation. In: Clinical standards manual. Minneapolis/St Paul (MN): Children's Hospitals and Clinics; 2004.

6. Tong R. Preventing extravasation injuries in neonates. Pediatr Nurs 2007; 19(8):22-25.

7. Extravasation of chemotherapy, prevention and management of. Policy III-20. Vancouver (BC): British Columbia Cancer Agency, Provincial Systemic Program Committee; 1997 [cited 2008 Oct 14]. Available from: www.bccancer.bc.ca/HPI/ChemotherapyProtocols/Policies.htm

8. Mader I, Furst-Weger PR, Mader RM, Negler-Semenitz E, Wassertheurer $\mathrm{S}$, editors. Extravasation of cytotoxic drugs: compendium for prevention and treatment. 2nd ed. New York (NY): Springer; 2009.

9. Yosowitz P, Ekland DA, Shaw CR, Parsons RW. Peripheral intravenous infiltration necrosis. Ann Surg 1975;182(5):553-556.

10. Mouridsen HT, Langer SW, Buter J, Eidtmann H, Rosti G, de Wit M, et al. Treatment of anthracycline extravasation with Savene (dexrazoxane): results from two prospective clinical multicentre studies. Ann Oncol 2007;18(3):546-550.

11. Bertelli G, Gozza A, Forno GB, Vidili MG, Silvestro S, Venturini M, et al. Topical dimethylsulfoxide for the prevention of soft tissue injury after extravasation of vesicant cytotoxic drugs: a prospective clinical study. $J$ Clin Oncol 1995;13(11):2851-2855.

Vanessa Paquette, BSC(Pharm), ACPR, is a Clinical Pharmacist, Neonata Critical Care, in the Department of Pharmacy, Children's and Women's Health Centre of British Columbia, and a Clinical Instructor in the Faculty of Pharmaceutical Sciences, The University of British Columbia, Vancouver, British Columbia. 
Rumi McGloin, BSc(Pharm), ACPR, PharmD, is the Pharmacy Education Supervisor, Residency Coordinator, and a Clinical Pharmacy Specialist, Pediatrics, in the Department of Pharmacy, Children's and Women's Health Centre of British Columbia, and is also a Clinical Assistant Professor in the Faculty of Pharmaceutical Sciences, The University of British Columbia, Vancouver, British Columbia.

Tracie Northway, RN, MSN, CNCCP(C), is Quality and Safety Leader, Department of Pediatric Critical Care, Children's and Women's Health Centre of British Columbia, Vancouver, British Columbia.

Pia DeZorzi, RN, BSCN, CPON, is Professional Practice Leader, Department of Nursing Administration, Children's and Women's Health Centre of British Columbia, Vancouver, British Columbia.

Avash Singh, MD, FRCPC, is a Neonatologist in the Division of Neonatology, Department of Pediatrics, Children's and Women's Health Centre of British Columbia and The University of British Columbia, Vancouver, British Columbia.
Roxane Carr, BSC(Pharm), PharmD, BCPS, FCSHP, is Clinical Leader, Pharmacy Critical Care Services, Department of Pharmacy, Children's and Women's Health Centre of British Columbia, and Assistant Professor (part-time), Faculty of Pharmaceutical Sciences, The University of British Columbia, Vancouver, British Columbia.

\section{Address correspondence to:}

Dr Roxane Carr

Pharmacy Department

Children's and Women's Health Centre of British Columbia

Room OB7, 4500 Oak Street

Vancouver BC V6H 3N1

e-mail: rcarr@cw.bc.ca 